\title{
THE EFFECT OF THE NITROIMIDAZOLE DRUG DIMETRIDAZOLE ON MICROAEROPHILIC CAMPYLOBACTERS
}

\author{
D. S. Fernie, D. A. Ware* and R. W. A. Park \\ Department of Microbiology, University of Reading, Reading RG1 $5 A Q$
}

THE antimicrobial nitroimidazole drugs, dimetridazole, metronidazole and tinidazole, are unusual in that they possess a wide spectrum of activity that has been reported to be limited to anaerobic bacteria and anaerobic protozoa (Prince et al., 1969; Edwards, Dye and Carne, 1973). Dimetridazole (1,2dimethyl 5-nitroimidazole) was introduced to combat histomoniasis in poultry, but has been more recently used extensively in the prevention and treatment of swine dysentery (Griffin, 1972). The aetiology of swine dysentery is not clear, but there is strong evidence that an anaerobic spirochaete, Treponema hyodysenteriae, plays an important role. The microaerophilic vibrio Campylobacter (Vibrio) coli (Véron and Chatelain, 1973) occurs in large numbers in the faeces of pigs with dysentery, and although doubts have been expressed as to whether it plays a part in the disease, we have found that campylobacters are required for the establishment of the disease (Fernie, Griffin and Park, 1975). We therefore wanted to examine the effect of dimetridazole on campylobacters to learn more about the aetiology of swine dysentery.

Campylobacters are oxidase positive and have an obligate requirement for oxygen except in the presence of nitrate, yet are poisoned by oxygen at its atmospheric partial pressure. Most workers have reported that campylobacters show optimum growth with 5 to $6 \%(\mathrm{v} / \mathrm{v}) \mathrm{O}_{2}$ in the gaseous phase, and do not grow either in air or in anaerobic conditions (Kiggins and Plastridge, 1956; Reich et al., 1957). Because of this obligate requirement for oxygenalbeit at less than normal atmospheric concentrations-one might expect from the literature that campylobacters would not be inhibited by dimetridazole. Thus, if they were resistant, the proven efficacy of dimetridazole in treating swine dysentery would seem to be incompatible with the view that campylobacters are involved in the disease. Our finding that campylobacters are sensitive to the agent caused us to examine the mode of action of dimetridazole in these organisms, since previous descriptions of how nitroimidazoles work had assumed that their antibacterial effect is linked with obligate anaerobiosis.

\section{MATERIALS AND METHODS}

Organisms. Eight strains of Campylobacter coli were isolated from the faeces of pigs with swine dysentery and 36 strains were isolated from rectal swabs of healthy pigs in several

Received 15 July 1976; revised version accepted 15 Nov. 1976. Ewell.

* Present address: Department of Biological Sciences, North East Surrey College of Technology,

J. MED. MICROBIOL.-VOL. 10 (1977) 
geographical areas by the methods of Morris and Park (1971). Campylobacter fetus subsp. intestinalis strain WII isolated from an aborted sheep foetus was provided by Mr R. Gambles, MAFF, Cattle Breeding Centre, Shinfield. C. fetus was included to represent related organisms causing diseases in other animals. The strains gave characteristic physiological reactions, i.e., type C and type B respectively (Morris and Park, 1973). Two strains of Escherichia coli (code numbered 16A and 16K) were from the departmental culture collection and a further two strains (nos. AG3 and SF3) were donated by Dr A. P. Regnier.

Media and cultural conditions. Yeast extract broth medium (YE) for physiological studies of campylobacters contained (g per litre of demineralised water): Yeast Extract (Difco), 5.0; $\mathrm{MgCl}_{2}, 0 \cdot 1 ; \mathrm{K}_{2} \mathrm{HPO}_{4}, 1 \cdot 0 ; \mathrm{KH}_{2} \mathrm{PO}_{4}, 0.5$; sodium citrate, $5.0 ; \mathrm{NaCl}, 5.0$; final $p \mathrm{H} \mathrm{7.0.}$ Blood agar consisted of Oxoid Blood Agar Base no. 2 plus defibrinated sheep blood to $10 \%$ (v/v). Campylobacters for experiments were grown by making $100 \mathrm{ml}$ of YE in a $250-\mathrm{ml}$ conical flask faintly turbid with organisms from a culture of the organism on blood agar grown at $37^{\circ} \mathrm{C}$ for $24 \mathrm{~h}$ in $30 \% \mathrm{CO}_{2}$ in air. The flask was then incubated statically in air for $18 \mathrm{~h}$ at $37^{\circ} \mathrm{C}$ followed by transfer to an orbital shaker $\left(150\right.$ r.p.m.) at $37^{\circ} \mathrm{C}$. Organisms were harvested during active growth as determined by observation of turbidity, washed once in an equal volume of culture of phosphate-buffered saline at $p \mathrm{H} \mathrm{7.0} \mathrm{(Oxoid} \mathrm{BR14a),} \mathrm{and} \mathrm{re-}$ suspended in phosphate-buffered saline to $1 / 100$ of the original volume. Bacteria were disrupted sonically at $100 \mathrm{~W}$ ( $8 \mu \mathrm{m}$ peak to peak) for $30 \mathrm{~s}$ with cooling in ice. Intact bacteria and cellular debris were removed by centrifugation at $7000 \mathrm{~g}$ for $10 \mathrm{~min}$.

$E$. coli strains were cultivated aerobically and anaerobically in a glucose nutrient broth containing (g per litre of demineralised water) Peptone (Evans) 5.0 ; Lab Lemco, 5.0; NaCl, 5.0 ; glucose, $10.0 \mathrm{~g}$; at $p \mathrm{H} \mathrm{7.0.}$

Sensitivity to dimetridazole. Sensitivity of campylobacters to dimetridazole was determined by subculturing growth from a culture of the organism on blood agar grown for $24 \mathrm{~h}$ in $30 \% \mathrm{CO}_{2}$ in air on to blood agar containing a known concentration of dimetridazole (May and Baker Ltd, Dagenham, England) previously added as a filter-sterilised solution to

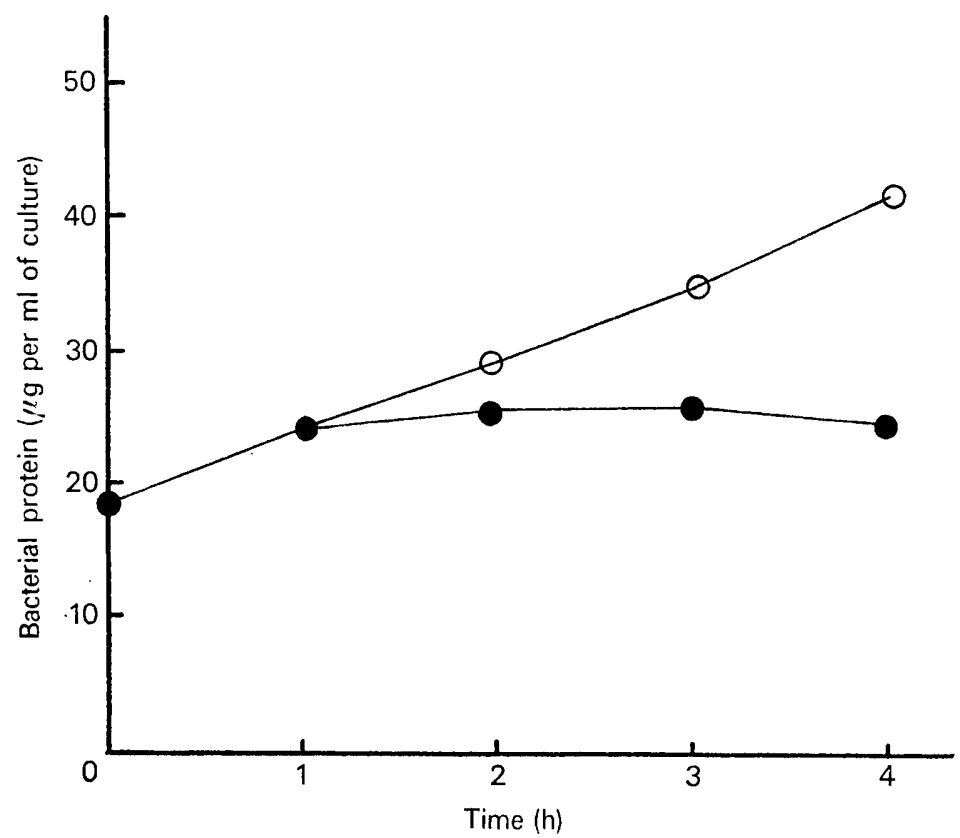

FIG. 1.-Effect of dimetridazole upon protein content of a shaken culture of Campylobacter coli in air: $=$ protein content after the addition of dimetridazole to $50 \mu \mathrm{g}$ per ml at time $0 ; 0=$ protein content in absence of dimetridazole. 
molten agar just before plates were poured. The inoculated medium was incubated for 5 days at $37^{\circ} \mathrm{C}$ in $30 \% \mathrm{CO}_{2}$ in air and then examined for surface growth. The MIC of dimetridazole was the smallest concentration (to $0.5 \mu \mathrm{g}$ per ml) that prevented growth of the strain.

Effect of dimetridazole on uptake of oxygen. Oxygen uptake was measured by an oxygen electrode (Rank Bros, Bottisham, Cambs.) connected to a Servoscribe potentiometric recorder. The electrode compartment, maintained at $37^{\circ} \mathrm{C}$, contained $0.2 \mathrm{ml}$ of a $100 \mathrm{~mm}$ solution of the substrate in phosphate saline, and $1 \mathrm{ml}$ of the dense suspension of whole or disrupted organisms in phosphate-buffered saline. Dimetridazole was added to a final concentration of 50 $\mu \mathrm{g}$ per ml once a steady uptake of oxygen after addition of the substrate had been established.

Estimations. Turbidity of samples from culture vessels was assessed with an Eel nephelometer head connected to an Eel galvanometer (Evans Electroselenium Ltd, Essex, England), set to 100 with a standard opaque tube. Protein was estimated by the Kennedy and Fewson (1968) modification of the Lowry method with crystalline bovine plasma albumin (Sigma) as standard.

For estimations of nucleic acids, campylobacters from $20 \mathrm{ml}$ of culture were washed in $\mathrm{MgCl}_{2}(1 \mathrm{mM})$ at $0-3^{\circ} \mathrm{C}$ and resuspended in $1 \mathrm{ml} \mathrm{MgCl}_{2}$ at $0-3^{\circ} \mathrm{C}$ and freeze-dried to 0.01 Torr in an EFO3 freeze dryer (Edwards, Crawley, England).

Total nucleic acids were extracted from each sample by the Scheider method as modified by Herbert, Phipps and Strange (1971). The DNA was estimated by the Burton (1956) diphenylamine method (standard: crystalline salmon sperm DNA, Sigma) and the RNA by the orcinol method as modified by Herbert et al. (1971) (standard: crystalline yeast RNA, Sigma). Extinctions were measured in a Hitachi-Perkins-Elmer 124 double-beam spectrophotometer.

\section{RESULTS}

\section{Sensitivity of organisms to dimetridazole}

All 44 strains of $C$. coli and the strain of $C$. fetus tested were sensitive to dimetridazole, the MICs of dimetridazole being between $0 \cdot 1$ and $10.0 \mu \mathrm{g}$ per ml. All four strains of $E$. coli were not inhibited by dimetridazole $100 \mu \mathrm{g}$ per ml whether grown aerobically or anaerobically.

Addition of dimetridazole at a final concentration of $50 \mu \mathrm{g}$ per ml to cultures of $C$. coli strain V6 and C. fetus strain WII, growing in a shaker in air, stopped increase in protein synthesis within 2 to $3 \mathrm{~h}$ (fig. 1). Turbidity of the culture also ceased to increase within 2 to $3 \mathrm{~h}$ after addition of the dimetridazole.

\section{Effect of dimetridazole on substrate oxidation}

According to Edwards et al. (1973), inhibition of anaerobic micro-organisms by nitroimidazoles is a consequence of the drug accepting electrons during pyruvate metabolism. In the energy-yielding metabolism of most microorganisms, pyruvate has one of three fates (fig. 2). In anaerobic metabolism it may be reduced to a fermentation product such as lactate or ethanol and this reduction is coupled to the oxidation of NADH, or it may undergo phosphoroclastic cleavage to acetyl-phosphate and then acetate with the reduction of a low-potential electron acceptor. In aerobic metabolism, pyruvate is normally reduced by the NAD-lipoate-linked pyruvate dehydrogenase complex to acetylCoA for oxidation via the citric-acid cycle. Campylobacters are obligate aerobes and have been shown to use the citric-acid cycle to metabolise compounds (Alexander, 1957; Lecce, 1958). Therefore it seemed reasonable to assume that pyruvate would be metabolised to acetyl $\mathrm{CoA}$ in the pyruvate 


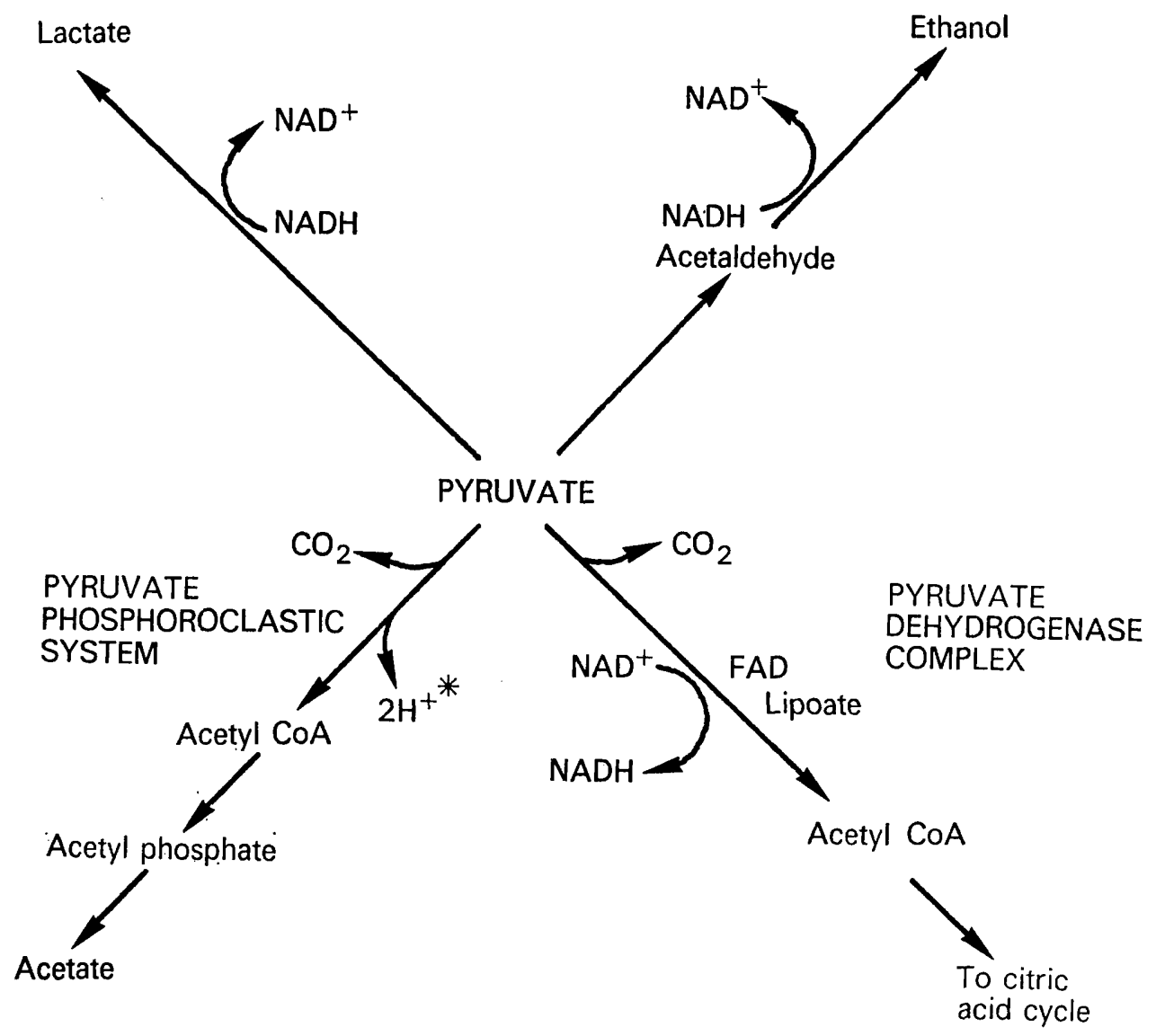

Fig. 2.-Major catabolic fates of pyruvate in micro-organisms.

* In clostridia, electrons are transferred to protons via ferredoxin and hydrogenase to form molecular $\mathbf{H}_{2}$. Other bacteria, e.g., species of Enterobacteriaceae, transfer electrons to the $\mathrm{CO}_{2}$ produced in the prior decarboxylation step to form formate.

dehydrogenase system involving NADH and $\mathrm{FADH}_{2}$. The effect of dimetridazole upon the oxygen uptake by campylobacters in the presence of pyruvate, succinate, or lactate was observed to see if dimetridazole accepted electrons from NADH or $\mathrm{FADH}_{2}$ and thereby inhibited electron transport and hence growth.

Endogenous respiration by washed $C$. coli was detected in the $\mathrm{O}_{2}$ electrode, and the addition of succinate or lactate but not pyruvate markedly increased $\mathrm{O}_{2}$ uptake. Pyruvate, NADH, succinate and lactate were each oxidised by disrupted organisms and by whole cells of $C$. fetus. The addition of dimetridazole at $50 \mu \mathrm{g}$ per $\mathrm{ml}$ did not alter the rate of oxygen uptake by any of these preparations within $20 \mathrm{~min}$.

These results suggested that (i) there could be a slow uptake of dimetridazole by intact bacteria so that inhibition of catabolism did not occur within the 20 min. test period (though catabolism of disrupted bacteria was also unaffected), 
or (ii) dimetridazole did not affect oxidation of the substrates tested, or (iii) that before inhibiting catabolism the dimetridazole must be converted to an active intermediate by a metabolic process that either did not occur in disrupted bacteria, or-less likely-took longer than $20 \mathrm{~min}$. to occur in disrupted bacteria.

To examine these possibilities, dimetridazole was added at a final concentration of $50 \mu \mathrm{g}$ per $\mathrm{ml}$ to an actively growing culture of $C$. fetus in YE medium. Even $90 \mathrm{~min}$. after the turbidity increase had ceased, samples from the culture displayed endogenous oxygen uptake and showed increased uptake of oxygen upon addition of pyruvate. Thus we concluded that the electron-transport system was still functioning and that inhibition of growth of campylobacters did not result from dimetridazole acting as an electron acceptor in pyruvate metabolism.

\section{Effect of dimetridazole on nucleic acid content}

Ings, McFadzean and Ormerod (1974) reported that metronidazole acted on sensitive micro-organisms by inhibiting nucleic-acid synthesis. Samples from a growing culture of $C$. coli in a shaking incubator in air at intervals before and after addition of dimetridazole to a final concentration of $50 \mu \mathrm{g}$ per ml were assayed for RNA and DNA.

Both DNA and RNA content per ml of culture continued to increase until $1 \mathrm{~h}$ after the addition of dimetridazole, after which no further increase could be demonstrated. The turbidity of the culture continued to increase until $2 \mathrm{~h}$ after addition of dimetridazole (fig. 3); then the increase stopped. There was no indication as to which nucleic acid was being affected first.

As the antimicrobial activity of nitroimidazoles is associated with the 1alkyl-5-nitroimidazole nucleus (Butler et al., 1967) which is structurally similar to the purine ring, it may be that dimetridazole acts as a substrate analogue of purines during nucleic-acid biosynthesis. To determine whether bases could inhibit competitively the effect of dimetridazole, campylobacters were grown in YE medium to which had been added one or more nucleoside solutions. Dimetridazole was added to a final concentration of $50 \mu \mathrm{g}$ per $\mathrm{ml}$, and the turbidity of the growing culture was observed to see if the inhibition of growth was delayed or prevented. The nucleosides tested-adenosine, cytidine, guanosine, uridine and thymidine-had no observable effect upon inhibition of growth by dimetridazole, whether added individually or together, to a final concentration of $50 \mu \mathrm{g}$ of each test nucleoside per $\mathrm{ml}$. These results suggest that dimetridazole is not acting as a base analogue or as a competitive inhibitor of nucleic-acid uptake or incorporation, but that dimetridazole or a metabolite of dimetridazole is specifically inhibiting a step essential for the biosynthesis of DNA and RNA.

\section{DISCUSSION}

Hitherto, nitroimidazoles have been regarded as inhibiting only anaerobes. The inhibition of microaerophilic campylobacters by dimetridazole demonstrates that this is not so. 
Our results suggest that an early effect of dimetridazole upon campylobacters is an inhibition of nucleic-acid synthesis. Inhibition of growth detected by serial determinations of turbidity and total protein occurs later. These findings are in accord with those of Ings $e$ t al. (1974) for metronidazole activity upon the anaerobic protozoan Trichomonas vaginalis and upon species of Clostridium. However, amounts of both nucleic acids in campylobacters continued to increase for $1 \mathrm{~h}$ after the addition of dimetridazole, This suggests (i) that dimetridazole enters the cell slowly, or (ii) that it must first be metabolised to an active inhibitor of nucleic acid biosynthesis, or (iii) that the site of its action is on the synthesis of a component essential for nucleic-acid biosynthesis.

Edwards et al. (1973) proposed that nitroimidazoles are active in microorganisms by accepting electrons from reduced ferredoxin during the catabolism

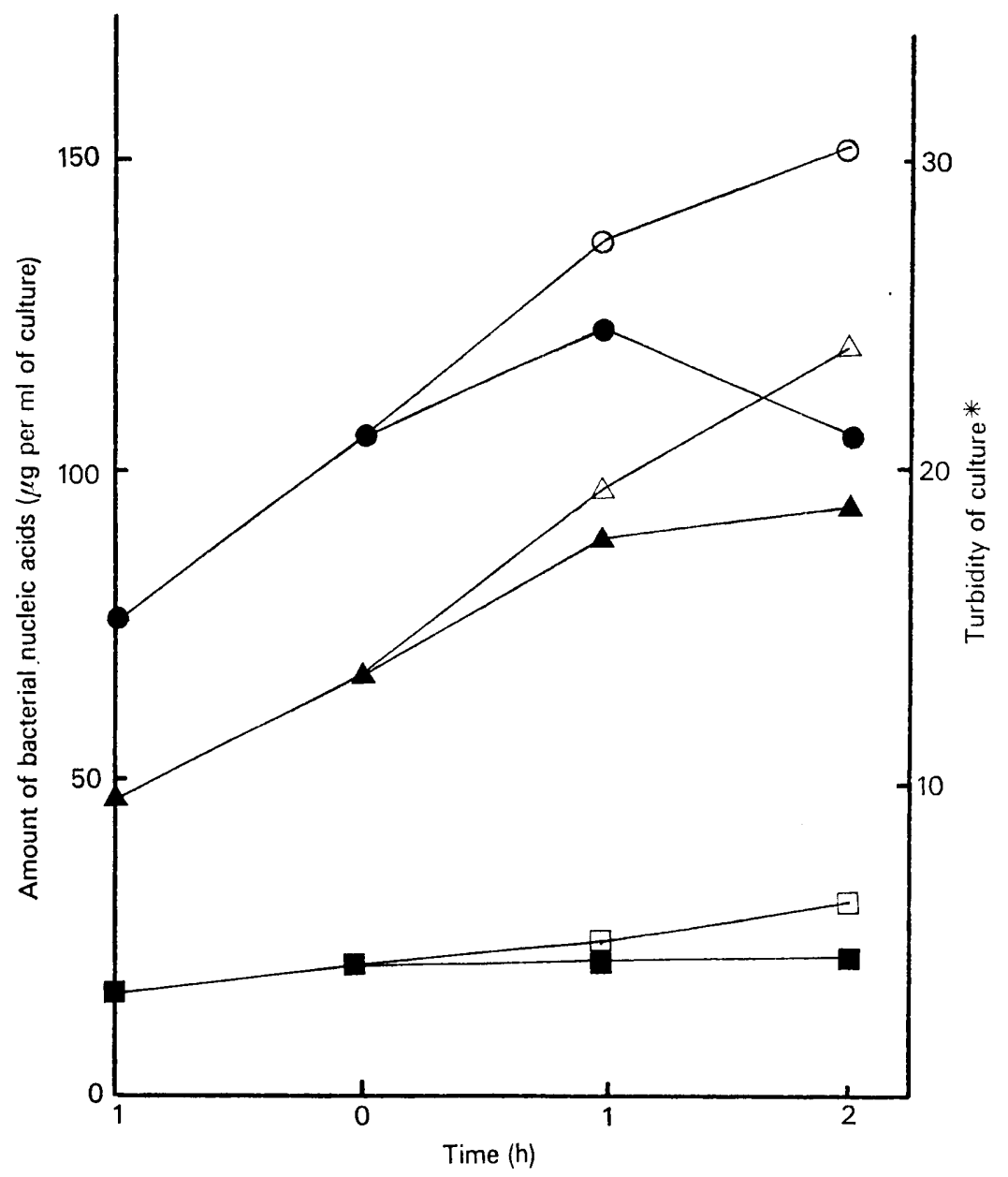

Fig. 3.-Effect of dimetridazole upon nucleic-acid content and turbidity of a shaken culture of C. coli in air. Estimations of RNA (-), DNA ( $\mathbf{(})$, and turbidity $(\boldsymbol{\Lambda})$ after addition of dimetridazole to $50 \mu \mathrm{g}$ per ml at time 0 . Estimations of RNA (O), DNA (ם), and turbidity $(\triangle)^{*}$ of control culture.

* Turbidity assessed by galvanometer readings with a nephelometer (see Methods). 
of pyruvate in a phosphoroclastic reaction, and that this results in reduced forms of the drug which are then lethal to micro-organisms. The explanation offered by these workers for the specificity of nitroimidazoles for anaerobes is that both the pyruvate phosphoroclastic reaction and ferredoxin are required for the reduction of the nitroimidazole to an active intermediate, and that these are not encountered in aerobic microbial systems. In fact, ferredoxins have been described in certain aerobic bacteria such as Azotobacter and Pseudomonas (Yoch and Valentine, 1972). The sensitivity of campylobacters to dimetridazole demonstrates that the activity of the nitroimidazoles is not restricted to organisms that metabolise pyruvate in a phosphoroclastic reaction. Furthermore, inhibition of growth of campylobacters by dimetridazole does not appear to be a consequence of the drug's interfering with electron transport in the catabolism of pyruvate. In the present study, dimetridazole was not active against $E$. coli growing anaerobically, but was active against campylobacters growing in a shaken culture in air. This offers further evidence that the toxicity of dimetridazole is not dependent upon the existence of an anaerobic metabolism.

Our findings show that previous explanations for the unusual spectrum of activity of nitroimidazoles are inadequate; any future hypothesis will have to take into account the activity of these drugs against the microaerophilic campylobacters. Furthermore, the level of sensitivity exhibited by strains of $C$. coli was similar to that shown by the anaerobic spirochaete $T$. hyodysenteriae (Griffin and Fernie, 1975), and this corroborates our previous findings that campylobacters seem to be involved in the aetiology of swine dysentery (Fernie et al., 1975).

\section{SUMMARY}

Dimetridazole, a nitroimidazole drug reported to act only on obligately anaerobic micro-organisms, is widely used for the prevention and treatment of swine dysentery. Forty-four strains of the microaerophilic bacterium Campylobacter coli isolated from either healthy or diseased pigs, and a strain of Campylobacter fetus, were all sensitive to dimetridazole. The sensitivities (minimal inhibitory concentration $<10 \mu \mathrm{g}$ per $\mathrm{ml}$ ) were similar to those of anaerobic bacteria. Dimetridazole inhibited growth of campylobacters in a shaken culture in air, but did not inhibit uptake of oxygen. Inhibition of growth appeared to result from an inhibition of nucleic-acid synthesis and does not seem to depend upon interference with electron transport in the catabolism of pyruvate.

We are grateful for financial support from the Agricultural and Science Research Councils, and May and Baker Ltd, during the course of this investigation.

\section{REFERENCES}

AleXander, J. K. 1957. Energy sources utilized by Vibrio fetus. J. Bact., 74, 168.

BURTON, R. K. 1956. A study of the conditions and mechanisms of the diphenylamine reaction for the colorimetric estimation of deoxyribonucleic acid. Biochem. J., 62, 315. 
Butler, K., Howes, H. L., LynCH, J. E. ANd PiRIE, D. K. 1967. Nitroimidazole derivatives. Relationship between structure and antitrichomonal activity. J. med. Chem., 10, 891.

Edwards, D. I., Dye, M. AND CaRne, H. 1973. The selective toxicity of antimicrobial nitroheterocyclic drugs. J. gen. Microbiol., 76, 135.

FernIE, D. S., GRIFfIN, R. M. AND PARK, R. W. A. 1975. The possibility that Campylobacter (Vibrio) coli and Treponema hyodysenteriae are both involved in swine dysentery. $\mathrm{Br}$. vet. J., 131, 335.

GRIFFIN, R. M. 1972. Therapeutic and prophylactic activity of dimetridazole against experimentally-transmitted swine dysentery. Vet. Rec., 91, 349.

Griffin, R. M. AND Fernie, D. S. 1975. The sensitivity in vitro to dimetridazole $(1,2-$ dimethyl-5-nitro-imidazole, $8595 \mathrm{RP}$ ) of spirochaetes (type 1) and Campylobacter coli isolated from pigs. In 20th World Veterinary Congress. Summaries. Thessaloniki, vol. 2, p. 993.

Herbert, D., Phipps, P. J. and Strange, R. E. 1971. Chemical analysis of microbial cells. In Methods in microbiology, edited by J. R. Norris and D. W. Ribbons, London, vol. 5B, p. 209.

Ings, R. M. J., McFadzean, J. A. ANd Ormerod, W. E. 1974. The mode of action of metronidazole in Trichomonas vaginalis and other micro-organisms. Biochem. Pharm., $23,1421$.

KENNEDY, S. I. T. AND Fewson, C. A. 1968. Enzymes of the mandelate pathway in bacterium N.C.I.B. 8250. Biochem. J., $107,497$.

Kiggins, E. M. AND Plastridge, W. N. 1956. Effect of gaseous environment on growth and catalase content of Vibrio fetus cultures of bovine origin. J. Bact., 72, 397.

LECCE, J. G. 1958. Some biochemical characteristics of Vibrio fetus and other related vibrios isolated from animals. J. Bact., 76, 312.

Morris, J. A. AND Park, R. W. A. 1971. The isolation of microaerophilic vibrios. In Isolation of anaerobes, edited by D. A. Shapton and R. G. Board, London, p. 207.

Morris, J. A. AND PARK, R. W. A. 1973. A comparison using gel electrophoresis of cell proteins of campylobacters (vibrios) associated with infertility and swine dysentery. J. gen. Microbiol., 78, 165.

Prince, H. N., Grunberg, E., Titsworth, E, and Delorenzo, W. F. 1969. Effects of 1-(2-nitro-1 imidazolyl)-3-methoxy-2 propanol and 2-methyl-5-nitroimidazole-1-ethanol against anaerobic and aerobic bacteria and protozoa. Appl. Microbiol., 18, 728.

Reich, C. V., Dunne, H. W., Bortree, A. L. And Hokanson, J. F. 1957. Technique for the rapid growth of Vibrio fetus in broth. J. Bact., 74, 246.

Véron, M. and Chatelain, R. 1973. Taxonomic study of the genus Campylobacter, Sebald \& Véron, and designation of the neotype strain for the type species, Campylobacter fetus (Smith \& Taylor) Sebald \& Véron. Int. J. syst. Bacteriol., 23, 122.

Yoch, D. C. AND Valentine, R. C. 1972. Ferredoxins and flavoproteins of bacteria. In Annual reviews of microbiology, edited by C. E. Clifton, S. Raffel and M. P. Starr, Palo Alto, California, vol. 26, p. 139. 